\title{
Haurdunaldian amak izandako bizi-ohiturak, ingurumen-esposizioak, osasun-sistemaren ekimenak eta haurraren garapen neuropsikologikoa. INMA (Haurtzaroa eta Ingurumena-Infancia y Medio Ambiente) proiektuan argitaratutako lanen errebisioa
}

(Mothers' lifestyle, environmental exposure and health system guidelines during pregnancy and children's neurodevelopment. A review of works published in the INMA (Environment and Childhood-INfancia y Medio Ambiente) project)

\author{
Izaro Babarro ${ }^{1,2 *}$, Ainara Andiarena ${ }^{1,2}$, Jesús Ibarluzea ${ }^{1,2,3,4}$, Eduardo Fano $^{1,2}$, Juan \\ Jose Aurrekoetxea ${ }^{1,2,3,4}$, Nerea Lertxundi $i^{1,2}$, Aitana Lertxundi ${ }^{1,2,4}$, Mara Gallastegi $i^{1}$, \\ Amaia Irizar ${ }^{1}$, Eva Pereda-Pereda ${ }^{1,2}$, Nerea Urbieta ${ }^{1}$, Loreto Santa Marina ${ }^{1,3,4}$ \\ ${ }^{1}$ Biodonostia Osasun Ikerketa Institutua. Donostia \\ ${ }^{2}$ Euskal Herriko Unibertsitatea, UPV/EHU \\ ${ }^{3}$ Osasun Saila. Eusko Jaurlaritza. Donostia \\ ${ }^{4}$ CIBER Epidemiología y Salud Pública (CIBERESP), Madril, Espainia.
}

\begin{abstract}
LABURPENA: Osasunaren esparruan oro har, eta zehazki Osasun Publikoarenean, azken bi mendeetan ingurumenak osasunean duen eragina aztertzeak interesa piztu du. Marc Lalondek, 1974. urtean osasun-eredua garatu zuen, eta azpimarratu zuen bizi-ohiturek eta inguruko faktoreek osasunean zuten eragina. Artikulu honen helburu orokorra da faktore hauek haurraren garapen neuropsikologikoan nola eragiten duten aztertzea helburutzat duten INMA proiektuko hainbat lanen emaitza esanguratsuenak azpimarratzea. Hala nola, emakumeen bizi-estiloekin erlazionatutako gainpisu/obesitateak eta erretze-ohiturak asoziazio negatiboa erakutsi zuten haurraren garapen neuropsikologikoarekin. Elikadura-ohiturei dagokienez, ikusi zen arraina osasunerako onuragarriak zein kaltegarriak diren substantzien garraio dela. Emakume haurdunek jarraitzen zituzten ekimenei dagokienez, gure proiektuko emaitzek erakutsi zuten azido folikoaren dosi altuegi zein baxuegiek haurren garapen neuropsikologikoan eragin positiboak zituztela. Edoskitze naturalak autismoa bezalako jokabide-arazoentzat eragin babesgarria zuela erakutsi zuten gure ikerketek. Ingurumen faktoreek haurraren garapenean eta osasunean kalteak dakartzatela ikusi da. Berdeguneek duten eragina, ordea, onuragarria dela ikusi da. Lan honek haurdunaldian emakumeak jarraitzen dituen bizi-ohiturak eta osasun-sistemaren aholkuak zein emakumeak dituen ingurumen-esposizioak haurraren garapen neuropsikologikoan duen eragina erakutsi du.

HITZ GAKOAK: Haurdunaldia, haurra, bizi-ohiturak, ingurumena, osasun sistema, garapen neuropsikologikoa, INMA proiektua.
\end{abstract}

ABSTRACT: In the health field in general and in public health in particular, the environment has become important over the last two centuries. In 1974 Marc Lalonde developed a health model, remarking the role that lifestyles and the environment play on health. The main objective of this work is to highlight the most relevant results of the INMA project in relation to how these factors impact the neuropsychological development of children. Among others, maternal lifestyles, overweight and obesity and tobacco habits showed a negative association with child neurodevelopment. Considering maternal diet during pregnancy we observed that fish consumption could be both beneficial and harmful for children neurodevelopment. Regarding the health guidelines, our results showed that folic acid had beneficial effects in children's neuropsychological development. Although extremely high doses of folic acid have been related to cognitive and psychomotor problems during childhood. Our study showed that breastfeeding is a protective factor against behavioral problems such as autism. Exposure to different particles that are in the environment had showed to have a negative effect in children neurodevelopment. The closeness to green spaces was related to an improvement of attention in children. This work concludes that mothers' lifestyles and sanitary patterns women follow during pregnancy, as well as their environmental exposure could be related to the future neuropsychological development of their children.

KEYWORDS: Pregnancy, child, lifestyles, environment, health system, neuropsychological development, INMA project.

* Harremanetan jartzeko / Corresponding author: Izaro Babarro, Ingurumen epidemiologia eta haurren garapena. BIODONOSTIA, Paseo Doctor Begiristain, zg (20014 Donostia-Gipuzkoa), Euskal Herria. - i-babarro@euskadi.eus - https://orcid. org/0000-0002-3626-7036.

Nola aipatu / How to cite: Babarro, Izaro; Andiarena, Ainara; Ibarluzea, Jesús; Fano, Eduardo; Aurrekoetxea, Juan Jose; Lertxundi, Nerea; Lertxundi, Aitana; Gallastegi, Mara; Irizar, Amaia; Pereda-Pereda, Eva; Urbieta, Nerea; Santa Marina, Loreto (2019). «Haurdunaldian amak izandako bizi-ohiturak, ingurumen esposizioak, osasun sistemaren ekimenak eta haurraren garapen neuropsikologikoa. INMA (Haurtzaroa eta Ingurumena - Infancia y Medio Ambiente) proiektuan argitaratutako lanen errebisioan; Ekaia, 36, 2019, 85-108. (https://doi.org/10.1387/ekaia.20417).

Jasoa: 26 azaroa, 2018; Onartua: 29 martxoa, 2019.

ISSN 0214-9001 - elSSN 2444-3255 / (C) 2019 UPV/EHU

(c) (i) (-) Obra hau Creative Commons Atribución 4.0 Internacional-en

c. ${ }_{\mathrm{BY}}$ NC SA lizentziapean dago 
Izaro Babarro et al.

\section{SARRERA}

1946. urtean Munduko Osasun Erakundeak (MOE) osasuna erabateko ongizate fisikotzat definitu zuen. Gaur egun, definizio honek onartua izaten jarraitzen du, nahiz eta ez dituen barnean beste faktore batzuk aintzat hartzen, hala nola, faktore endogenoak (gizabanakoaren biologiaren menpe daudenak) edota faktore exogenoak (ingurumena, inguru fisikoa).

Osasunaren esparruan eta, zehazki, Osasun Publikoarenean, ingurumenak indarra hartu zuen Xx. mendean. 1974. urtean Marc Lalondek osasun-eredua garatu zuenean, bizi-ohiturek eta inguruko faktoreek osasunean zuten eragina finkatu zen. Lalondek, gizabanakoarengan edo gizartean eragina duten inguruko faktore multzotzat definitu zituen osasun-determinatzaileak, eta, haien artean, bi talde nagusi desberdindu zituen. Alde batetik, Estatuaren erantzukizun direnak eta bestetik, osasun-arloaren menpe daudenak. Osasun-determinatzaileen artean, giza biologia, bizi-ohiturak, ingurumena eta osasun-sistemaren menpeko eragileak desberdindu zituen [1].

Ildo honetan, INMA (Infancia y Medio Ambiente-Haurtzaroa eta Ingurumena) proiektuak (www.proyectoinma.org) ingurumen kutsatzaileekiko esposizio goiztiarra eta honek haurraren osasunean duen eragina aztertzea du helburu nagusitzat Estatuan zehar dauden 7 azpi-kohorteetan. Zehazki, INMA sarearen hasieran sortu ziren hiru kohorte (Menorca, Flix-Tarragona eta Granada) eta lau ex novo sortuak izan ziren (Asturias, Gipuzkoa, Sabadell eta Valentzia) [2].

INMA proiektuak ikerketa ugari egin du, haurrek jaio aurretik zein haurtzaroan zehar dituzten bizi-ohitura eta esposizioek beren garapenean eta osasunean duten eragina aztertzeko.

Lan honen helburua da emakumeek haurdunaldian izandako bizi-ohiturek, osasun-sistemaren ekimenek eta ingurumen-esposizioek haurraren garapen neuropsikologikoan duten eragina aztertzea, INMA proiektuan garatu diren lanen berrikuspen bat eginaz.

\section{MATERIALA ETA METODOAK}

Bilaketa bibliografikoa Biblioteca Virtual de la Salud, Dialent, Pubmed eta Web of Science datu-baseetan egin zen, eta erabili ziren hitz gakoak «pregnancy», «child», «neuropsychological development» eta «INMA project» izan ziren. Bilaketa bibliografikoan 192 artikulu agertu ziren, eta horietatik 23 artikuluk inklusio- eta baztertze-irizpideak betetzen zituzten. Beste bi artikulu, datu-base horietan egon ez arren, gaiarekin lotura zuzena izateagatik erabaki zen berrikusketa honetan sartzea. Bat Osagaiz aldizkari ez-indexatuan argitaratua izan zen [13] eta bestea, argitaratzeke dago [14]. 
Haurdunaldian amak izandako bizi-ohiturak, ingurumen-esposizioak, osasun-sistemaren ekimenak eta haurraren garapen neuropsikologikoa

1. taula. Inklusio- eta baztertze-irizpideak.

\begin{tabular}{|c|c|}
\hline Inklusio-irizpideak & Baztertze-irizpideak \\
\hline $\begin{array}{l}\text { - Haurraren garapen neuropsikologikoa } \\
\text { } 14 \text { hilabete eta - } 8 \text { urte bitartean ebalua- } \\
\text { tzen duten lanak. } \\
\text { - Aldagai asketzat haurren amek haurdunal- } \\
\text { dian zehar dituzten eragileak. } \\
\text { - Lalonderen determinatzaileen artean, bi- } \\
\text { zi-ohiturak, ingurumen-esposizioak edo } \\
\text { osasun-sistemarekin erlazionaturiko era- } \\
\text { gileak ikertzen dituzten lanak. } \\
\text { - INMA proiektuko lanak izatea. }\end{array}$ & $\begin{array}{l}\text { - Aldagai asketzat haurtzaroko lehen urtee- } \\
\text { tan haurrek izandako eragileak aztertzen } \\
\text { dituzten artikuluak. } \\
\text { - Lalonderen determinatzaileen artean gi- } \\
\text { zabanakoaren biologiarekin lotura duten } \\
\text { eragileak aztertzen dituzten lanak. } \\
\text { - INMA proiektuko lanak ez izatea. }\end{array}$ \\
\hline
\end{tabular}

\subsection{Menpeko aldagaia: garapen neuropsikologikoa}

INMA proiektuko familiei haurdunalditik fase desberdinetan egin zaie jarraipena, eta haurren garapen neuropsikologikoa, fase bakoitzean, jarraian zehazten diren instrumentuak erabiliz ebaluatu da:

- 14 hilabete: Haurtzaroko garapena ebaluatzeko Bayley eskala (BSID: Bayley Scale Infant Development) [3].

-4 urte:

- Haurraren gaitasunak eta psikomotrizitatea ebaluatzeko McCarthy eskala (MSCA: McCarthy Scales of Childrens Ability) [4].

- Asperger sindromea eta autismoaren sindromea ebaluatzen duen CAST (Childhood Autism Spectrum Test) eskala [5].

\section{-8 urte:}

- Arreta-arazoak ebaluatzeko ANT testa (Attention Network Task) [6].

- Lan-oroimena ebaluatzen duen, N-Back Testa [7].

- Arreta Defizita eta Hiperaktibitatearen Nahasmena (ADHN) ebaluatzeko Conners eskala [8].

\subsection{Aldagai askea: bizi-ohiturekin, ingurumenarekin eta osasun-ekimenekin erlazionatutako eragileak}

Aztertutako eragileen artean, amaren ezaugarri soziodemografikoak, dieta, bizimoduak, osasun-egoera aurkitzen dira, besteak beste. Datu hauek guztiak galdetegiak erabiliz eta aurretik prestakuntza jasotako profesionalek bideratutako elkarrizketen bitartez jaso ziren, fase desberdinetan. Horrez gain, emakume eta haurren lagin biologikoak jaso eta froga desberdi- 
nak egin ziren. Gainera, airearen kalitatea eta kontsumoko uraren kalitatea ere neurtu ziren.

\section{EMAITZAK ETA EZTABAIDA}

Aztertu diren 25 artikuluetako sei bizi-ohiturekin [9-14], hamaika ingurumenarekin [15-25] eta zortzi osasun-sistemak emandako jarraibideekin [26-33] daude erlazionatuta.

\begin{tabular}{|c|c|c|c|}
\hline Bizi-ohiturak & Ingurumena & $\begin{array}{l}\text { Osasun } \\
\text { Sistema }\end{array}$ & Giza Biologia \\
\hline $\begin{array}{l}\text {-Elikadura- } \\
\text { ohiturak } \\
\text {-Obesitatea } \\
\text { eta gainpisua } \\
\text {-Erretze- } \\
\text { ohiturak }\end{array}$ & $\begin{array}{l}\text {-Aireko } \\
\text { partikulak } \\
\text {-Uretan } \\
\text { aurkitzen diren } \\
\text { partikulak } \\
\text {-Berdeguneak }\end{array}$ & $\begin{array}{l}\text { - lodo } \\
\text { kontsumoa } \\
\text {-Azido foliko } \\
\text { kontsumoa } \\
\text {-Edoskitze } \\
\text { naturala }\end{array}$ & $\begin{array}{l}\text {-Ez da aztertu } \\
\text { lan honetan. }\end{array}$ \\
\hline
\end{tabular}

1. irudia. Lalonde txostenean proposatutako osasun-determinatzaileekin lotura duten eta INMA proiektuan aztertu diren eragileak. 
Haurdunaldian amak izandako bizi-ohiturak, ingurumen-esposizioak, osasun-sistemaren ekimenak eta haurraren garapen neuropsikologikoa

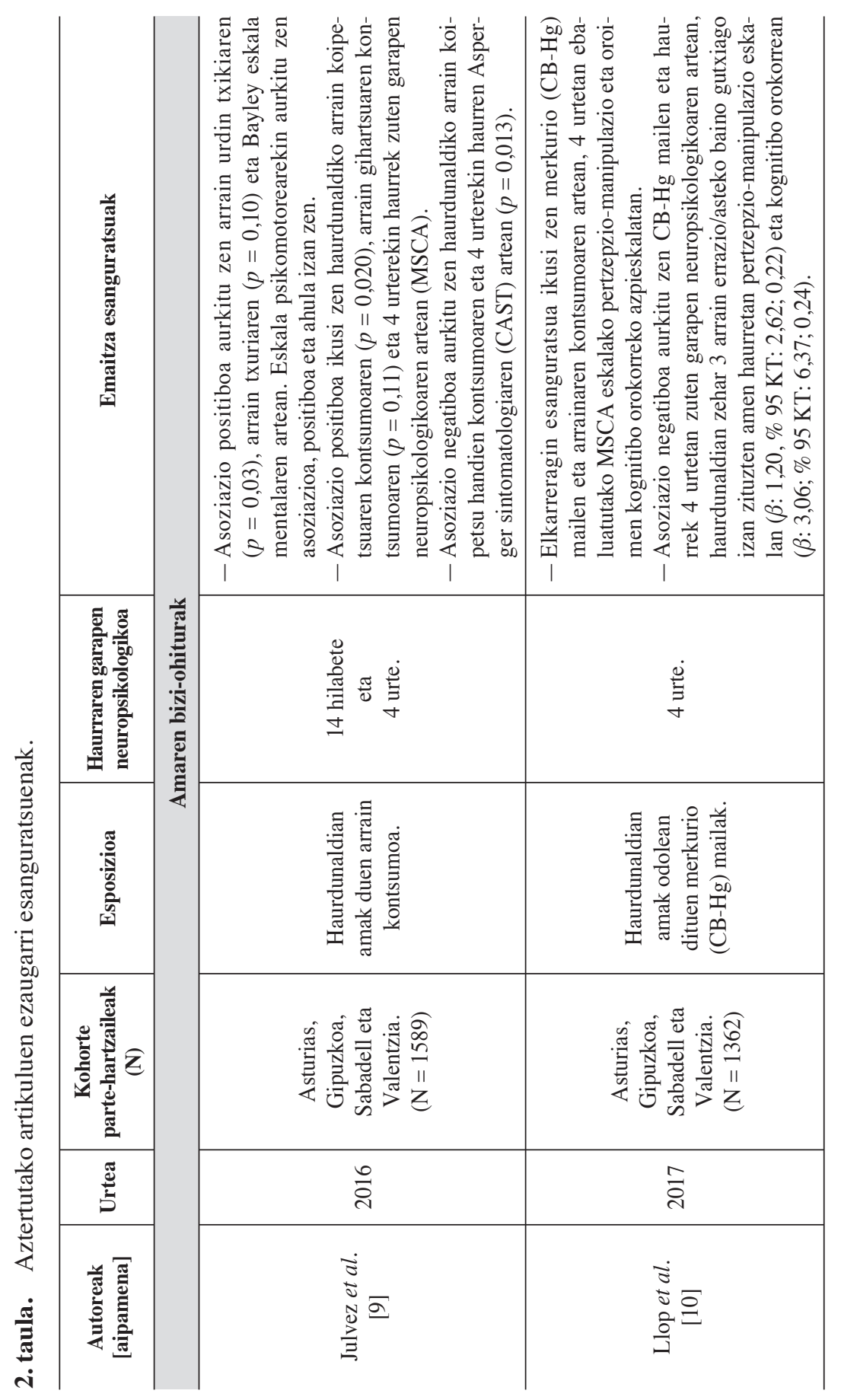

https://doi.org/10.1387/ekaia.20417 
Izaro Babarro et al.

\begin{tabular}{|c|c|c|c|}
\hline 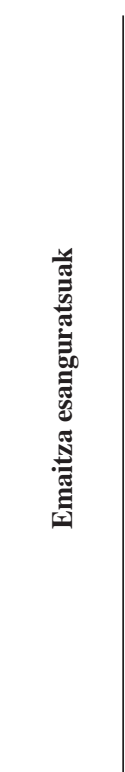 & 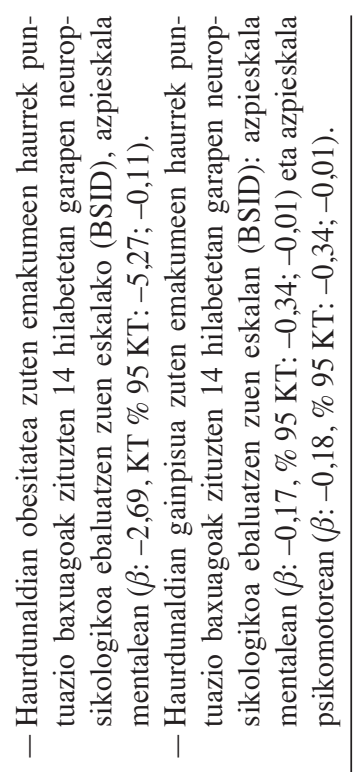 & 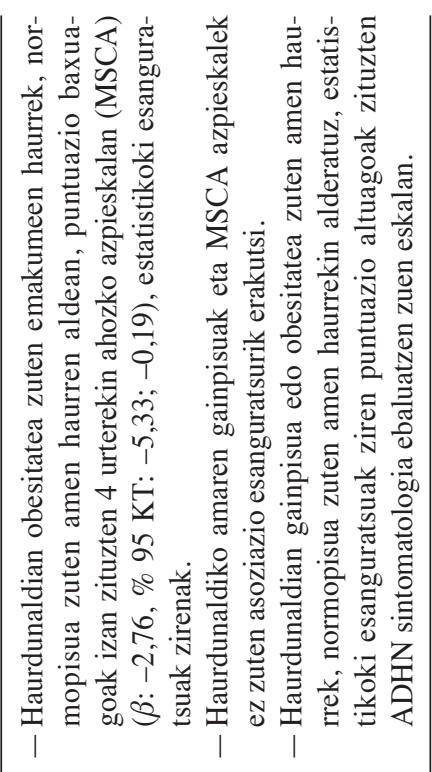 & 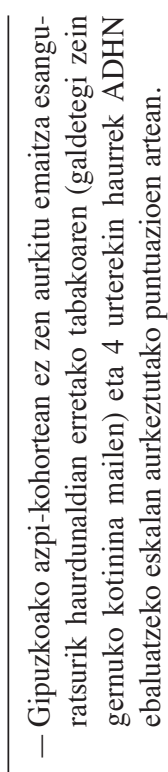 \\
\hline 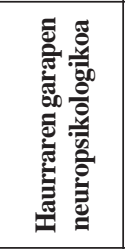 & 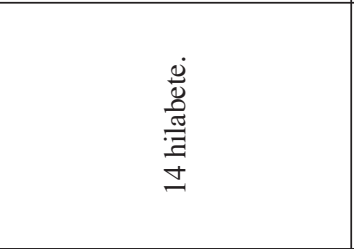 & 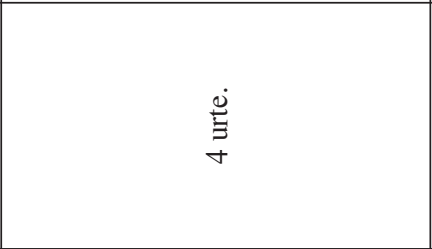 & $\underset{⿱ 亠 凶}{\stackrel{\Xi}{\Xi}}$ \\
\hline 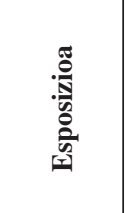 & 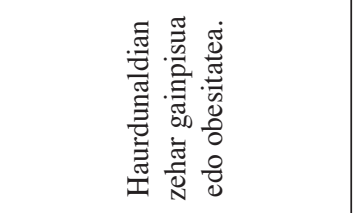 & 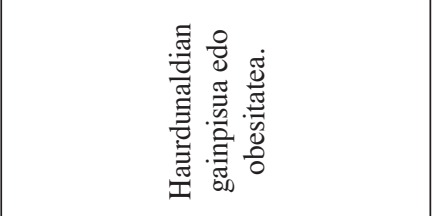 & 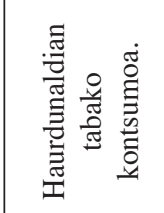 \\
\hline 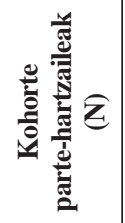 & 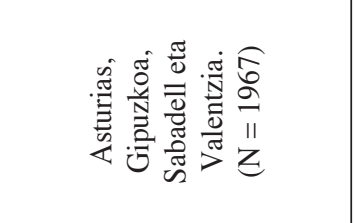 & 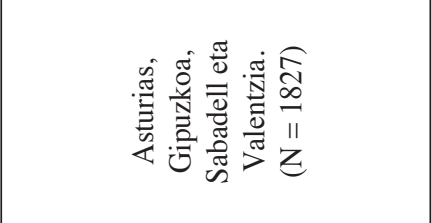 & 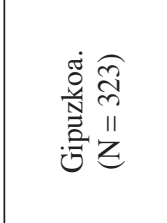 \\
\hline$\stackrel{\Xi}{5}$ & $\stackrel{m}{\stackrel{n}{n}}$ & $\stackrel{\bar{\sim}}{\circ}$ & $\overline{\text { సิ }}$ \\
\hline 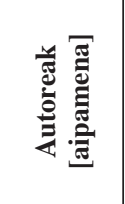 & 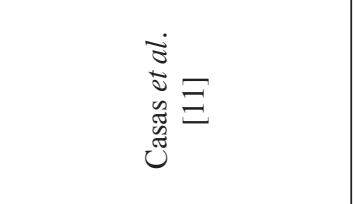 & $\begin{array}{l}\dot{\Xi} \\
\dot{\Xi} \Xi \\
\tilde{\Xi} \Xi \\
\tilde{J} \\
\tilde{J}\end{array}$ & 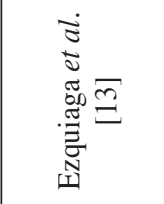 \\
\hline
\end{tabular}


Haurdunaldian amak izandako bizi-ohiturak, ingurumen-esposizioak, osasun-sistemaren ekimenak eta haurraren garapen neuropsikologikoa

\begin{tabular}{|c|c|c|c|c|}
\hline 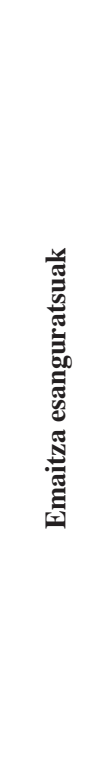 & 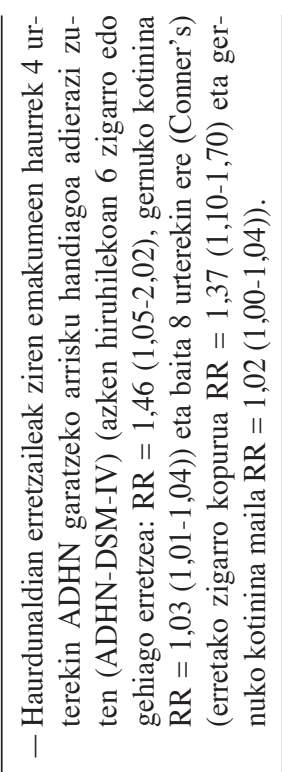 & \multirow{6}{*}{ 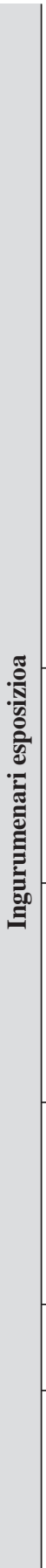 } & 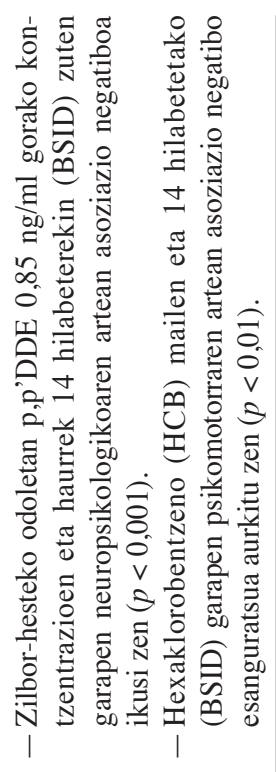 & 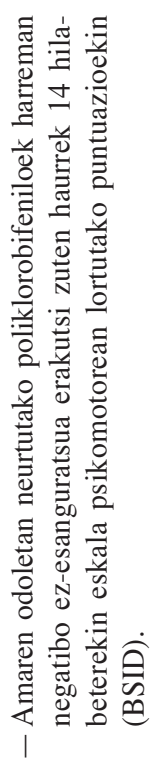 \\
\hline 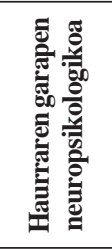 & 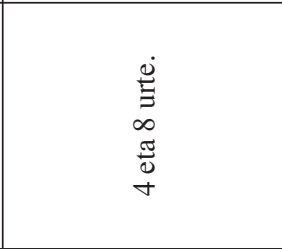 & & 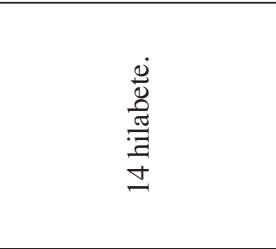 & 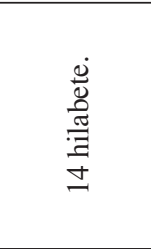 \\
\hline 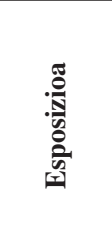 & 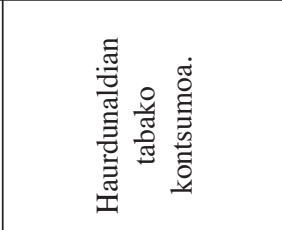 & & 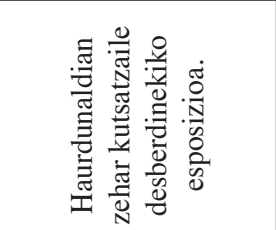 & 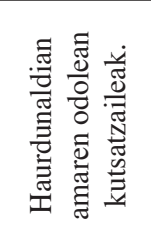 \\
\hline そ气 & 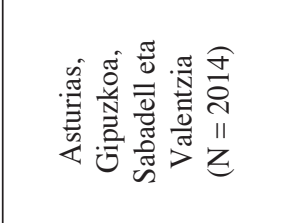 & & 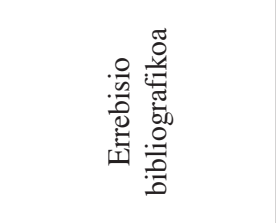 & 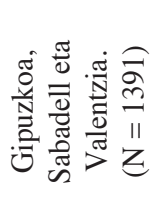 \\
\hline$\frac{\$}{5}$ & 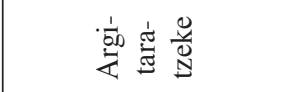 & & $\stackrel{\sim}{\stackrel{i}{1}}$ & $\stackrel{\sim}{\stackrel{\lambda}{1}}$ \\
\hline 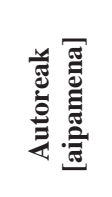 & 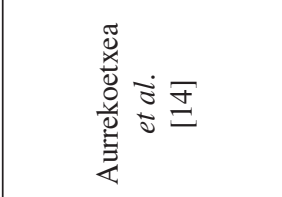 & & 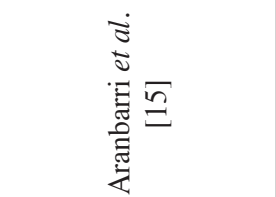 & 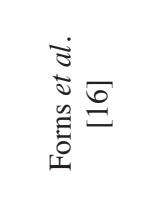 \\
\hline
\end{tabular}


Izaro Babarro et al.

\begin{tabular}{|c|c|c|c|}
\hline 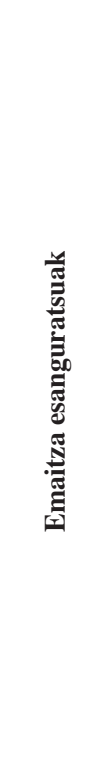 & 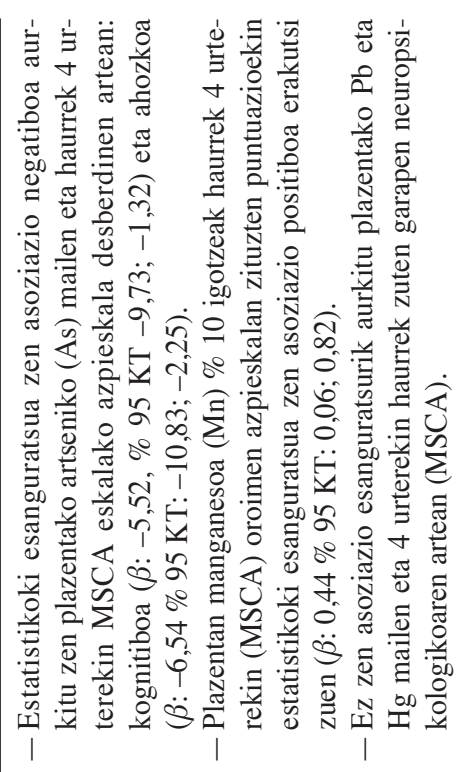 & 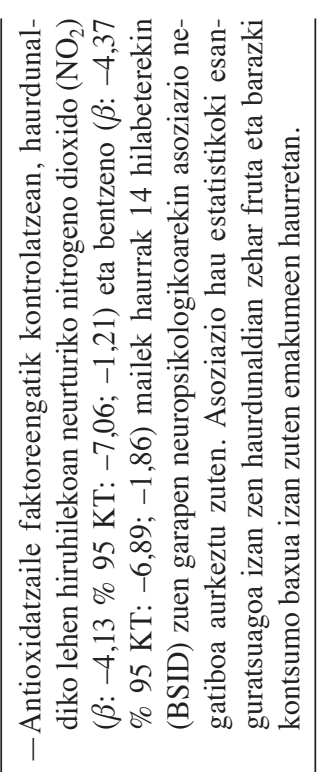 & 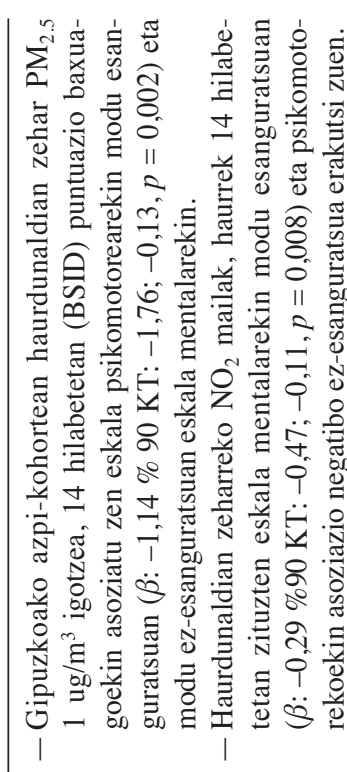 \\
\hline 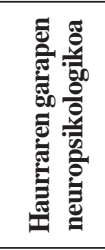 & 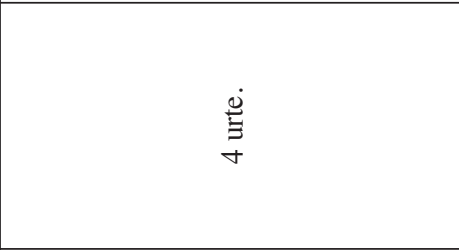 & 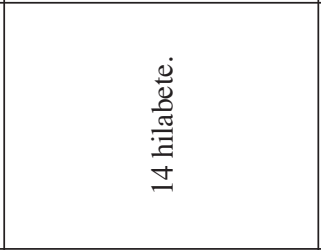 & 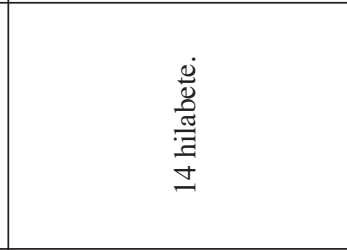 \\
\hline 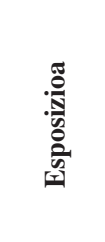 & 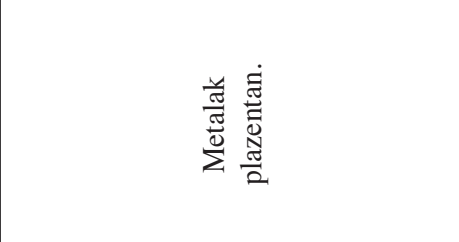 & 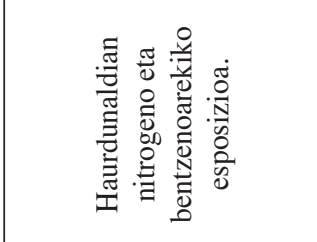 & 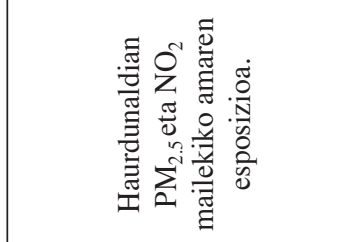 \\
\hline 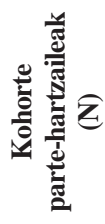 & 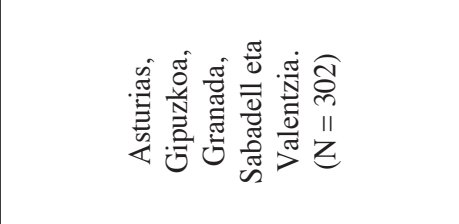 & 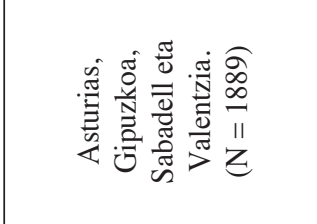 & 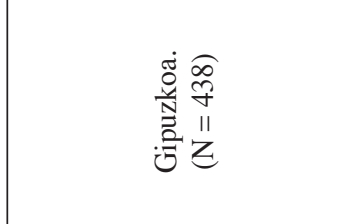 \\
\hline ฐ & $\stackrel{\infty}{\stackrel{\sim}{c}}$ & 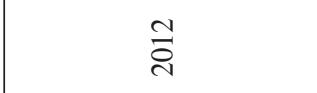 & $\stackrel{n}{\frac{\pi}{d}}$ \\
\hline 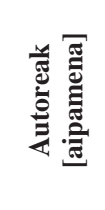 & 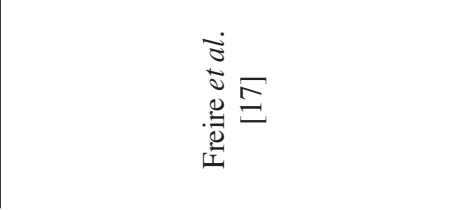 & 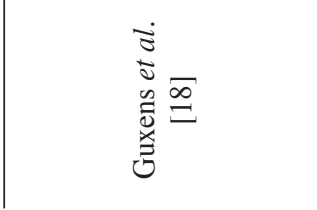 & 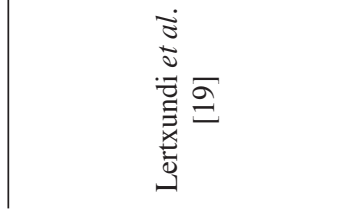 \\
\hline 92 & & & Ekaia, 2019, 3 \\
\hline
\end{tabular}


Haurdunaldian amak izandako bizi-ohiturak, ingurumen-esposizioak, osasun-sistemaren ekimenak eta haurraren garapen neuropsikologikoa

\begin{tabular}{|c|c|c|c|c|}
\hline 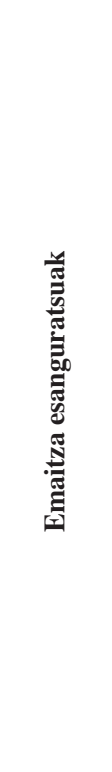 & 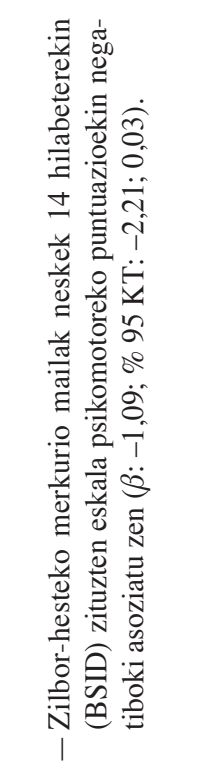 & 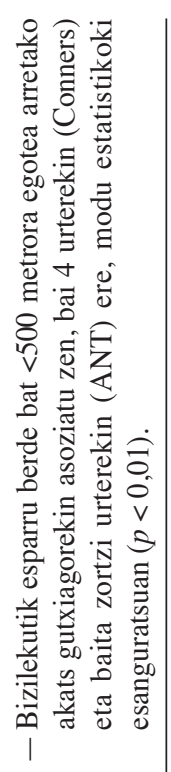 & 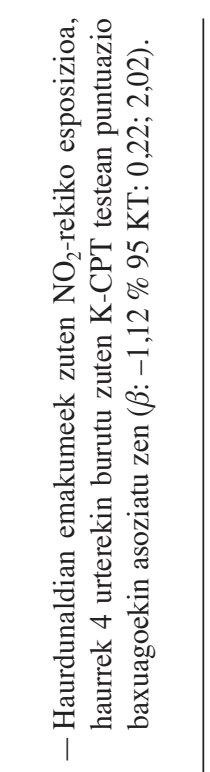 & 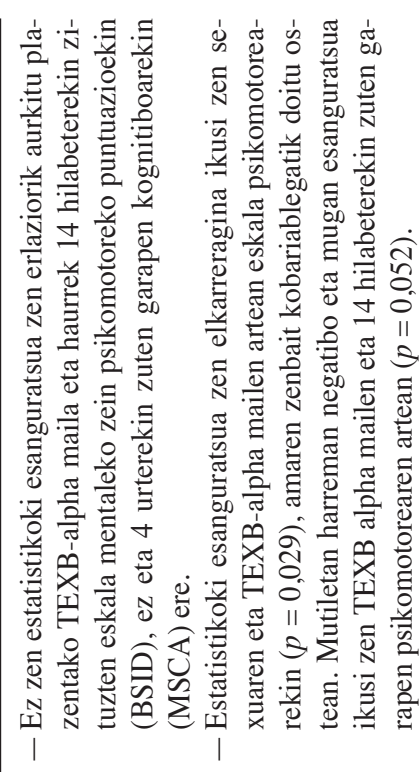 \\
\hline 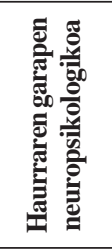 & 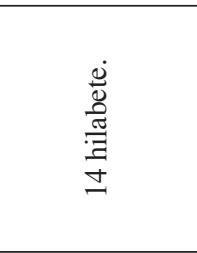 & $\begin{array}{l}\stackrel{0}{\Xi} \\
\Xi \\
\infty \\
\frac{\pi}{0} \\
\dot{\sigma}\end{array}$ & $\underset{\stackrel{\Xi}{\Xi}}{\stackrel{\dot{\Xi}}{ }}$ & $\begin{array}{l}\frac{\dot{0}}{0} \\
\frac{0}{\pi} \\
\frac{\Xi}{\Xi} \\
\text { ป }\end{array}$ \\
\hline 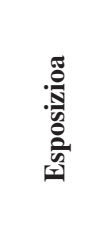 & 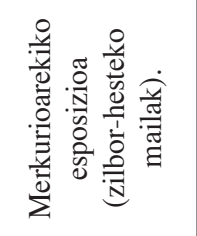 & 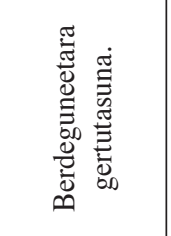 & 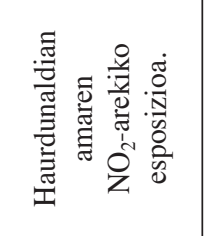 & 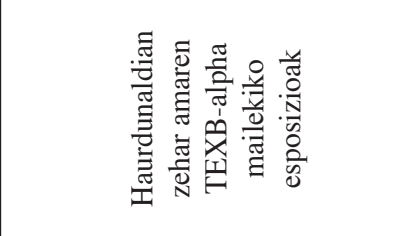 \\
\hline 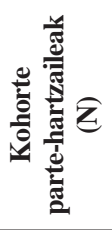 & 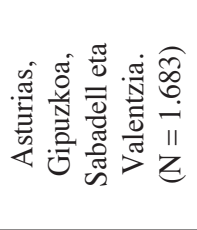 & 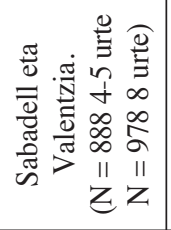 & 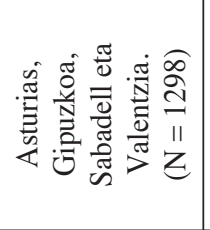 & 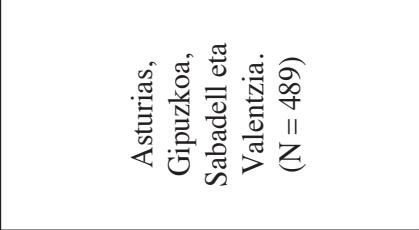 \\
\hline 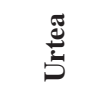 & $\stackrel{\sim}{\stackrel{\sim}{*}}$ & $\stackrel{\nabla}{\stackrel{\sim}{*}}$ & $\overrightarrow{\mathrm{d}}$ & $\underset{\stackrel{d}{~}}{\Delta}$ \\
\hline 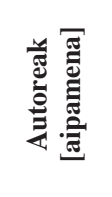 & 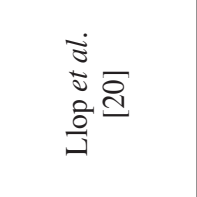 & 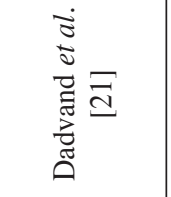 & 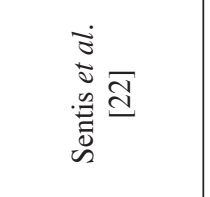 & 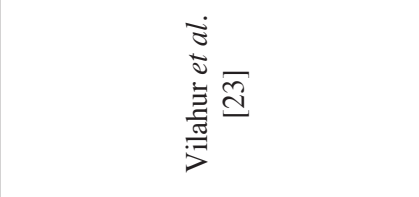 \\
\hline
\end{tabular}

https://doi.org/10.1387/ekaia.20417 
Izaro Babarro et al.

\begin{tabular}{|c|c|c|c|c|}
\hline 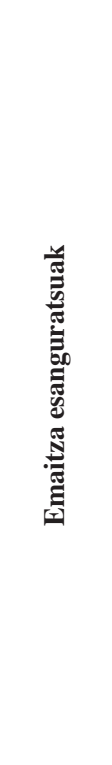 & 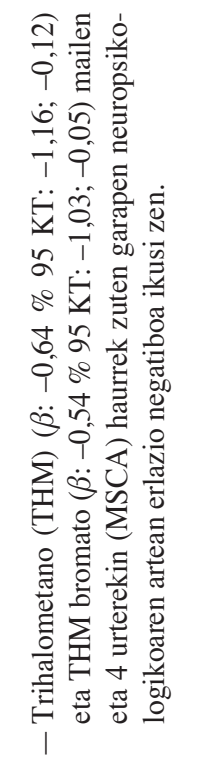 & 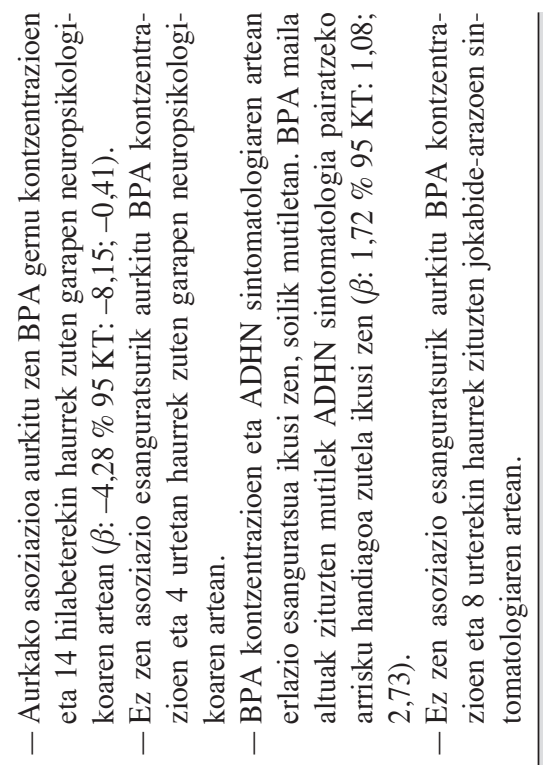 & \multirow{6}{*}{ 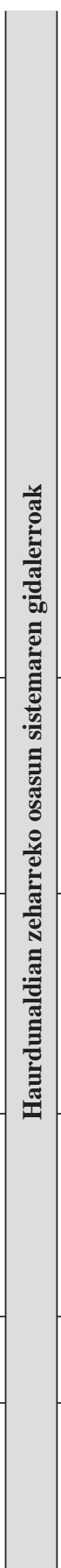 } & 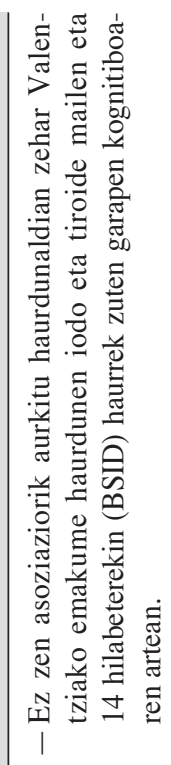 \\
\hline 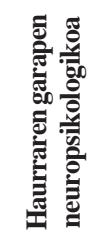 & $\begin{array}{l}\stackrel{\stackrel{\Xi}{\Xi}}{\Xi} \\
\underset{\nabla}{ }\end{array}$ & 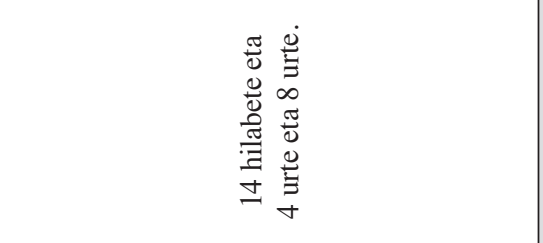 & & $\begin{array}{l}\frac{0}{0} \\
\frac{0}{0} \\
\frac{0}{3} \\
\text { ป }\end{array}$ \\
\hline 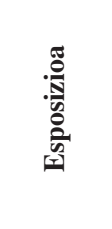 & 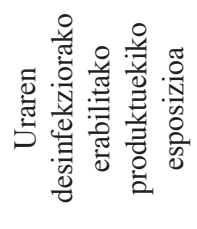 & 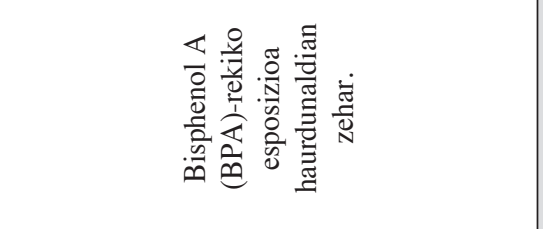 & & 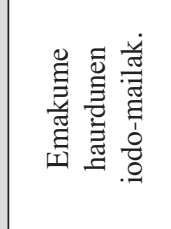 \\
\hline 施 & 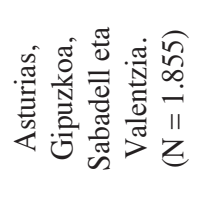 & 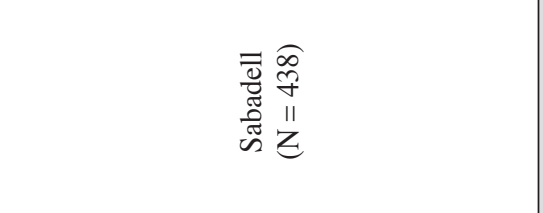 & & 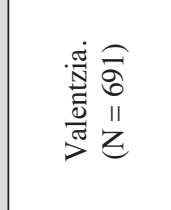 \\
\hline$\underset{\Xi}{5}$ & $\stackrel{\bar{i}}{\vec{i}}$ & $\frac{n}{\grave{2}}$ & & $\overline{\mathrm{c}}$ \\
\hline 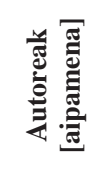 & 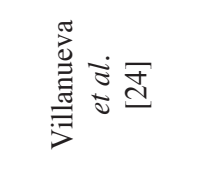 & 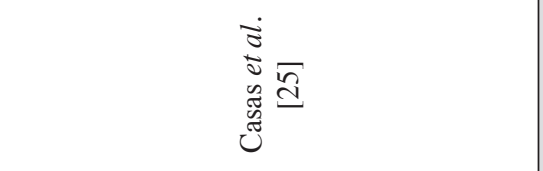 & & 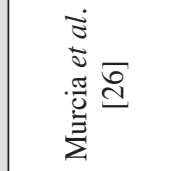 \\
\hline
\end{tabular}


Haurdunaldian amak izandako bizi-ohiturak, ingurumen-esposizioak, osasun-sistemaren ekimenak eta haurraren garapen neuropsikologikoa

\begin{tabular}{|c|c|c|c|}
\hline 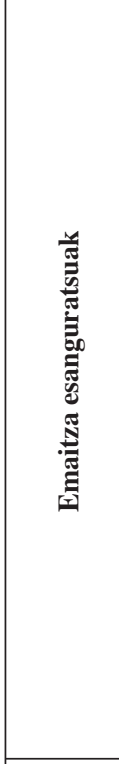 & 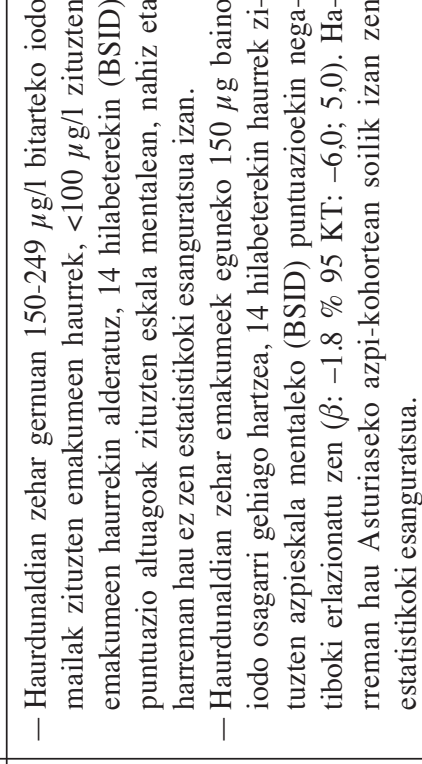 & 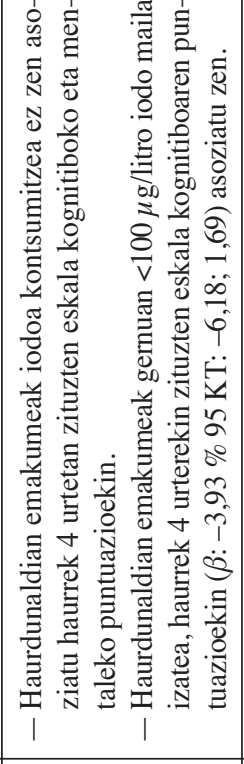 & 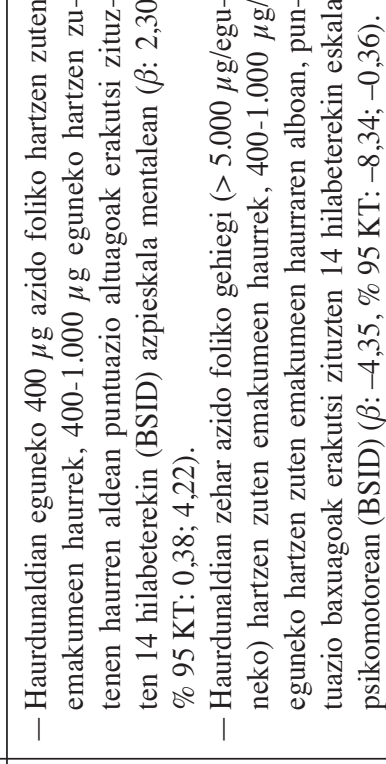 \\
\hline 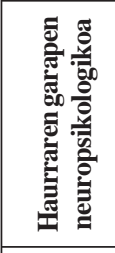 & 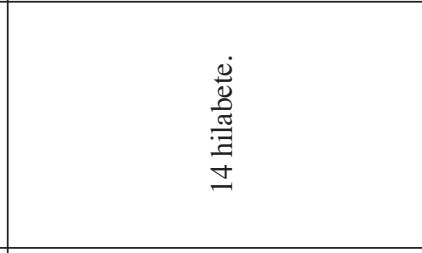 & 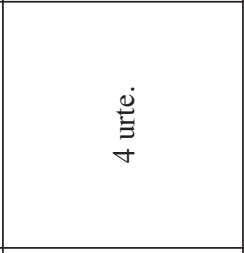 & 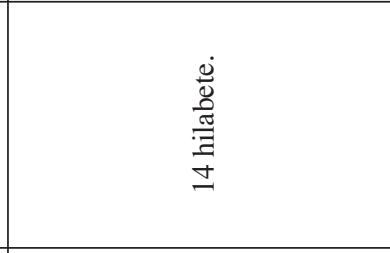 \\
\hline 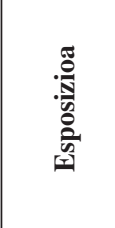 & 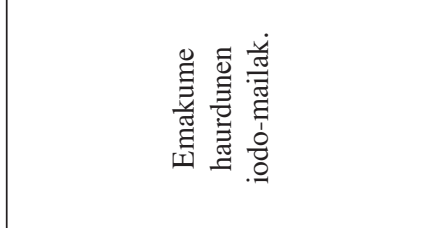 & 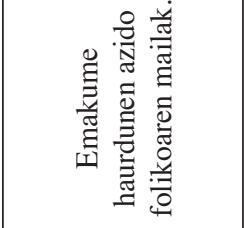 & 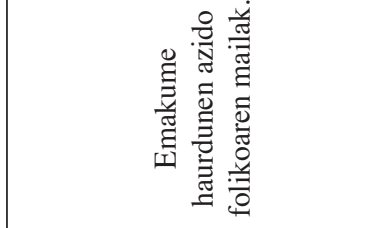 \\
\hline 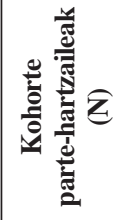 & 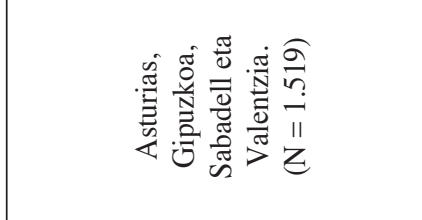 & 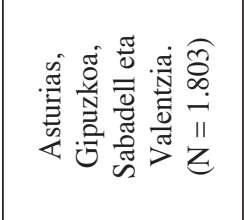 & 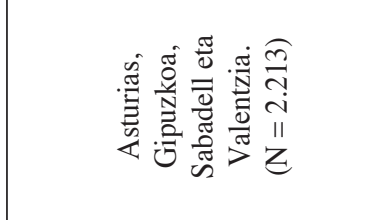 \\
\hline$\frac{\pi}{5}$ & $\stackrel{\sim}{\vec{\alpha}}$ & $\overrightarrow{\mathrm{d}}$ & $\stackrel{\Delta}{\vec{c}}$ \\
\hline 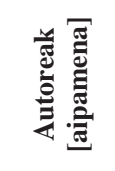 & 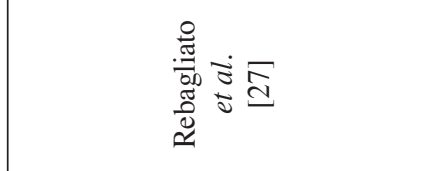 & 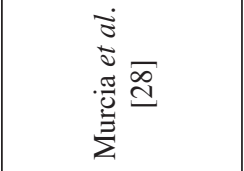 & 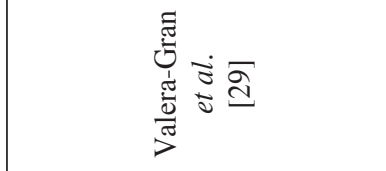 \\
\hline
\end{tabular}


Izaro Babarro et al.

\begin{tabular}{|c|c|c|c|}
\hline 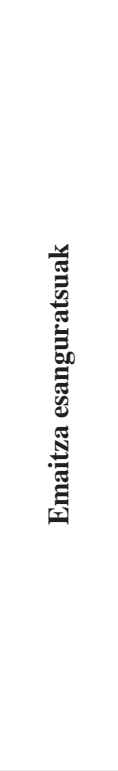 & 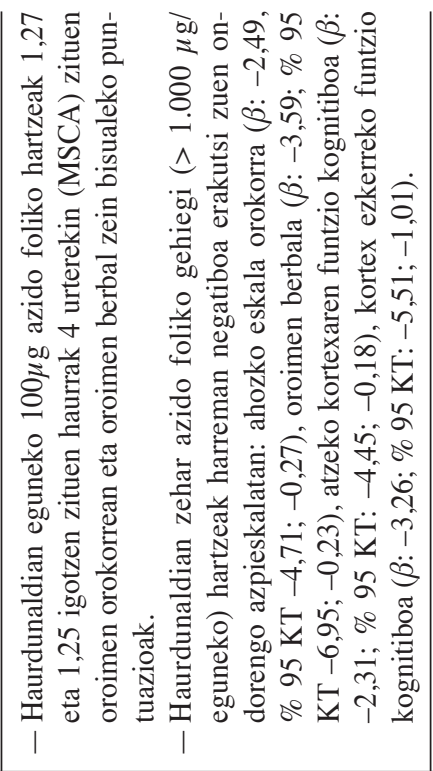 & 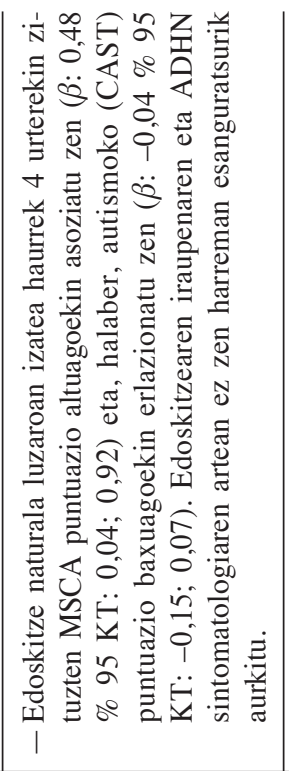 & 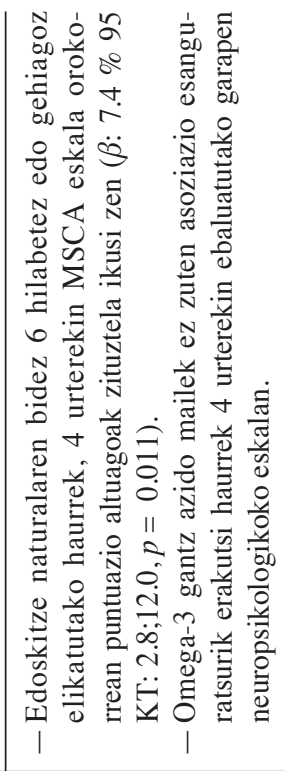 \\
\hline 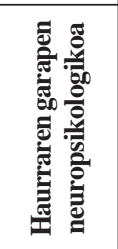 & $\underset{⿱ 亠 䒑}{\stackrel{\Xi}{\Xi}}$ & 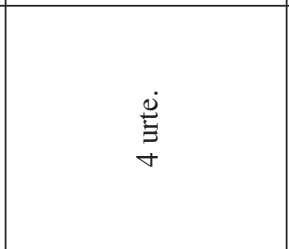 & $\underset{⿱ 亠 䒑}{\stackrel{\Xi}{\Xi}}$ \\
\hline 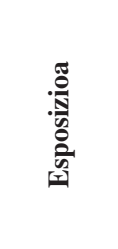 & 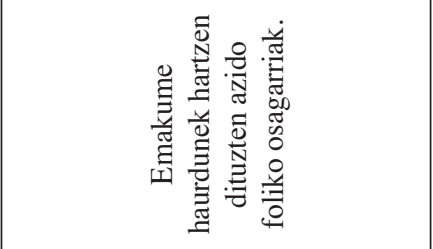 & 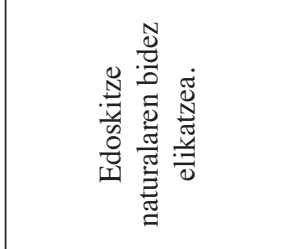 & 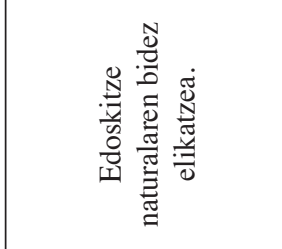 \\
\hline 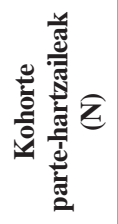 & 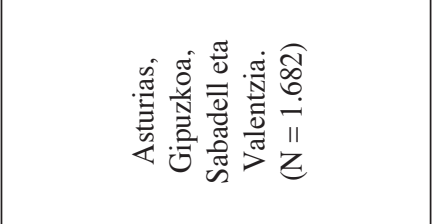 & 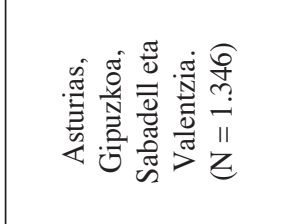 & 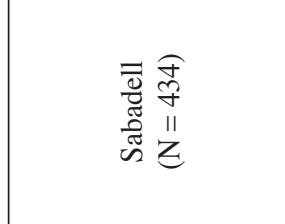 \\
\hline 苞 & $\overline{\vec{i}}$ & $\stackrel{\circ}{\circ}$ & $\stackrel{\nabla}{\stackrel{\sim}{\sim}}$ \\
\hline 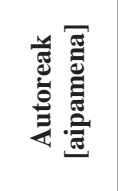 & 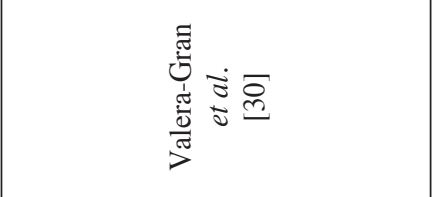 & 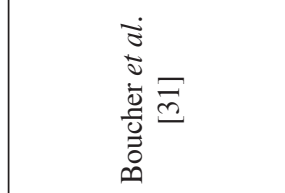 & 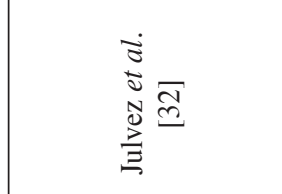 \\
\hline
\end{tabular}


Haurdunaldian amak izandako bizi-ohiturak, ingurumen-esposizioak, osasun-sistemaren ekimenak eta haurraren garapen neuropsikologikoa

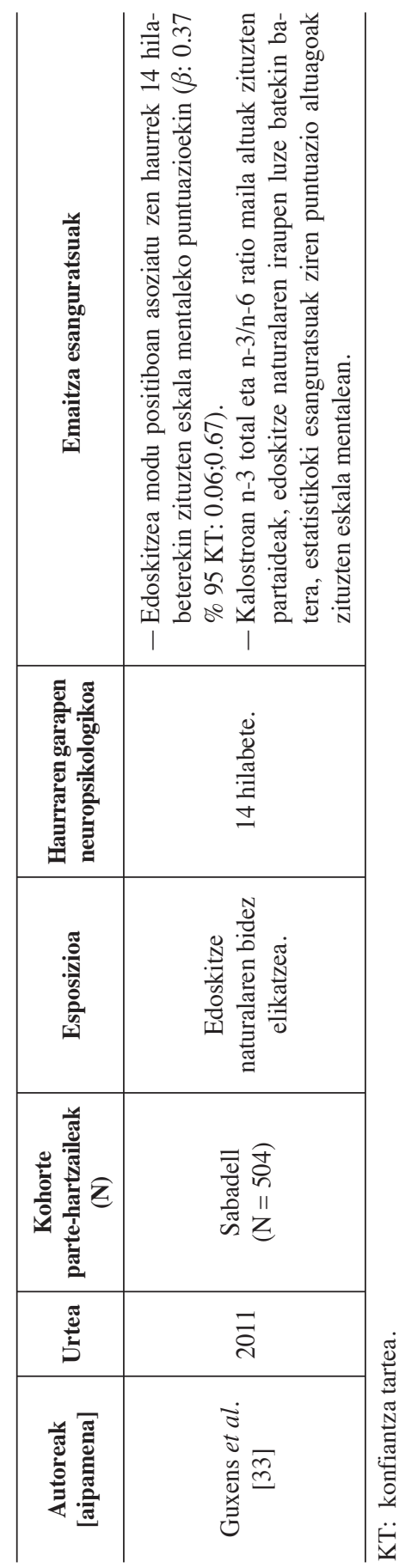

https://doi.org/10.1387/ekaia.20417 
Izaro Babarro et al.

\subsection{Amaren bizi-ohiturekin lotura duten eragileak}

Bizimodua pertsonak dituen ohitura multzoek osatzen dute, eta haien artean elikadura, alkohola eta tabako-kontsumoa edota ariketa fisikoa aurkitzen dira, besteak beste.

\subsubsection{Haurdunaldiko elikadura-ohiturak eta haurraren garapen neuropsikologikoa}

Emakumeak haurdunaldian jarraitutako dietak eragin handia du umekiaren garapenean eta hazkuntzan.

INMA proiektuan, emakumeak haurdunaldian izandako arrain-kontsumoak asoziazio positiboa erakutsi zuen haurrak 14 hilabetetan (BSID) eta 4 urtetan (MSCA) zuen garapen neuropsikologikoarekin; eta negatiboa, Asperger sintomatologiarekin (CAST) [9]. Horrez gain, zilbor-hesteko odoleko merkurio (CB-Hg) mailek harremana erakutsi zuten haurdunaldian zehar hiru arrain errazio baino gutxiago hartzen zituzten emakumeen haurretan, zeinak 4 urterekin garapen neuropsikologiko baxuagoa zuten (MSCA) [10]. Emakume haurdunen elikadurak haurraren garapenean duen eragina erakutsi duten lanak aurkitu dira [34-36].

\subsubsection{Haurdunaldian emakumeak gainpisua edo obesitatea izatea eta haurraren garapen neuropsikologikoa}

Obesitatea, kaloria gehiegi hartzeagatik eta ariketa fisiko gutxi egiteagatik gertatzen den, eta mundu-mailan \% 30eko prebalentzia duen osasunarazoa da [37]. Gaur egun, onartzen da obesitatearen ondorioz gorputzean hantura-prozesu bat gertatzen dela eta horrek haurraren garapen kognitiboan eta portaeran eragina duela [38-39].

INMA proiektuan, gainpisua eta obesitatea zuten emakumeen haurrek garapen neuropsikologiko okerragoa zuten 14 hilabeterekin (BSID) eta 4 urterekin (MSCA) [11], eta, arrisku handiagoa erakutsi zuten ADHN sintomatologia adierazteko [12]. Asoziazio hauek aztertu dituzten ikerketen artean, ildo beretik doazen emaitzak [38], eta aldagai hauen artean asoziaziorik ikusi ez dutenak daude [40]. Emaitza desberdinak aurkitzearen arrazoietako bat, azken ikerketa honetan, besteetan ez bezala, haurraren garapen neuropsikologikoa testen bitartez ebaluatu ez izana izan daiteke.

\subsubsection{Tabako-kontsumoa eta haurraren jokabidearen arteko harremana}

Emakume batek haurdunaldian erretzen duenean, tabakoaren kutsatzaile asko plazenta zeharkatu eta fetura iristen dira. Horregatik, erretzen duten emakumeen haurrek arazo gehiago izan ditzakete garapen neuropsikologikoan [41]. 
Haurdunaldian amak izandako bizi-ohiturak, ingurumen-esposizioak, osasun-sistemaren ekimenak eta haurraren garapen neuropsikologikoa

INMA-Gipuzkoako azpi-kohortean ez zen asoziaziorik aurkitu haurdunaldian erretze-ohituraren eta haurrek lau urterekin zuten ADHN sintomatologiaren artean [13]. Kohorte guztietan asoziazio hau aztertzean, emakume erretzaileen haurrek lau eta zortzi urterekin ADHN izateko arrisku handiagoa adierazi zutela ikusi zen [14]. Emaitza desberdin hauek laginaren ezaugarriekin erlazionatuta egon daitezke, Gipuzkoako emakumeek klase sozial altuagoa eta tabako-kontsumo baxuagoa baitzuten. Gai honi buruzko ikerketa gehienek asoziazio positiboa erakutsi dute emakumeen erretze-ohituraren eta haurraren jokabide-arazoen artean [42-43].

\subsection{Ingurumenarekin erlazionaturiko faktoreak}

\subsubsection{Ingurumeneko kutsatzaileekiko esposizioa}

Ingurumen-kutsatzaileak giza aktibitatearen ondorioz sortzen diren sustantzia kimiko, fisiko zein biologikoak dira. Uretan, airean, lurrean eta elikagaietan aurkitzen dira, gizarteari gehienetan esposizio baxu baina orokortua ekarriz.

\subsubsection{Konposatu organiko iraunkorrekiko (KOI) eta substantzia inorganikoekiko esposizioek haurraren garapen neuropsikologikoan duten eragina}

Nerbio sistema zentrala (NSZ) garapenean dago fase enbrionariotik bizitzako lehen urteak arte, eta agente kimiko iraunkorren erasoen aurrean bereziki kaltebera da [15]. Umekia eta jaioberria substantzia hauen eraginpean daude plazentaren eta edoskitzearen bitartez, eta kalte neuronala sor diezaiekete [44].

INMA proiektuko ikerketek jaio aurreko PCB (bifenilo polikloratuak) eta merkurio mailen eta 14 hilabeteko haurraren garapen psikomotorearen (BSID) artean harreman negatiboa erakutsi zuten [45]. Sustantzia hauen eta garapen neuropsikologikoaren arteko asoziazioa aurkitu duten ikerketak daude [46-47]. INMA proiektuan plazentan neurtutako metalen mailak 4 urterekin haurrak zuen garapenarekin erlazionatzean, artsenikoaren (As) eta MSCA azpieskalen artean asoziazio negatiboa ikusi zen; Manganeso (Mn) mailek, aldiz, erlazio positiboa erakutsi zuten eskala bereko puntuazioekin [17].

\subsubsection{2. $\mathrm{NO}_{2}$ eta $\mathrm{PM}_{2.5}$ haurdunaldian zeharreko esposizioa eta haurraren garapen neuropsikologikoa.}

Haurraren garapen neuropsikologikoarekin asoziazioa erakutsi duten kutsatzaile atmosferikoak honako hauek dira: hidrokarburo aromatiko poliziklikoak (PAHk) [48], nitrogeno dioxidoa $\left(\mathrm{NO}_{2}\right)$, bentzenoa, karbono beltza eta $10 \mu \mathrm{m}$ baino diametro txikiagoko partikulak $\left(\mathrm{PM}_{10}\right)$ [49]. 
Izaro Babarro et al.

Gipuzkoako azpi-kohortean emakume haurdunek zenbait partikularen aurrean esposizioa izateak $\left(\mathrm{PM}_{2.5}\right.$ eta $\left.\mathrm{NO}_{2}\right)$ asoziazio negatiboa erakutsi zuen haurrak 14 hilabetetan zuen garapen kognitibo eta motorearekin (BSID) [19]. Kutsatzaile hauekiko esposizioa 4 azpi-kohortetan aztertzean, bentzenoak eta $\mathrm{NO}_{2}$-ak haurraren garapenean eragin negatiboa zuela sumatu zen [18]. Proiektuan jasotako emaitzak bat datoz ingurumen-kutsatzaile atmosferikoen eta garapen neuropsikologikoaren arteko asoziazioa erakusten duen ikerketarekin [49].

\subsubsection{Haurdunaldian berdeguneetatik gertu egoteak haurraren garapen neuropsikologikoan duen eragina}

Berdegune terminoak landarediaren presentziari egiten dio erreferentzia. Berdeguneetatik gertu egotea zaratarekiko eta aire kutsadurarekiko esposizio baxuago batekin eta ariketa fisikoa sustatzearekin erlazionatu da [50-52]. Herbehereetan [53] eta Estatu Batuetan [54] egindako ikerketek erakutsi dute berdeguneek asoziazio positiboa duela haurrak 12 urterekin duen arrakasta akademikoarekin. INMA proiektuak, bestalde, adierazi du beren bizilekutik $500 \mathrm{~m}$ baino gertuagora gune berde bat duten haurrek arreta mantentzeko arazo gutxiago dituztela bai 4 urterekin (K-CPT) bai eta 8 urterekin (ANT) ere [21].

\subsubsection{Desinfektaturiko uraren kontsumoa eta haurraren garapen neuropsikologikoa}

Uraren desinfekzioa ezinbestekoa da patogenoekin amaitu eta uraren bitartez transmititzen diren infekzioak prebenitzeko. Uraren desinfekzioan kloroa erabiltzen da batik bat, eta hura uretan dagoen materia organikoarekin erreakzionatzean bi produktu sortzen dira: Trihalometanoa (THM) eta azido haloazetikoa (HAA). Gizakiok substantzia hauekin kontaktua bide desberdinen bitartez izaten dugu (edaterakoan, arnasterakoan edo azalaren kontaktuaren bitartez) [55].

INMA proiektuan, haurdunaldian amak THM eta THM bromatuetara esposizio altua izatea erlazionatu zen 4 urtetan haurrek eskala kognitiboan puntuazio baxuagoak izatearekin (MSCA) [24].

\subsection{Osasun-sistemarekin erlazionatutako eragileak}

Osasun-sistemaren ekimenarekin lotura duten bi faktore aztertu dira lan honetan. Alde batetik, osagarri farmakologikoak (iodoa eta azido folikoa), eta bestetik, edoskitze naturala. 
Haurdunaldian amak izandako bizi-ohiturak, ingurumen-esposizioak, osasun-sistemaren ekimenak eta haurraren garapen neuropsikologikoa

\subsubsection{Haurdunaldian amak duen iodo-kontsumoaren eta haurraren garapen neuropsikologikoaren arteko asoziazioa.}

Iodoa oinarrizko elikagaia da, eta ezinbestekoa da hormona tiroideen sintesirako, zelulen metabolismorako eta organo guztien garapen eta funtzionamendurako, bereziki, garunarentzat. Haurdunaldian emakumeak iodo eskasia izateak edo iodo gehiegi hartzeak eragina du emakumearentzat eta umekiarentzat [56].

INMA proiektuko ikerketek erakutsi zuten haurdunaldian zehar gernuan 150-249 $\mu \mathrm{g} / \mathrm{l}$ zituzten emakumeen haurrek, $<100 \mu \mathrm{g} / \mathrm{l}$ zituzten emakumeen haurrekin alderatuz, garapen neurologiko baxuagoa zutela 14 hilabeterekin (BSID). Bestalde, emakumeek iodoa osagarri bitartez $>150 \mu \mathrm{g} /$ eguneko dosian hartzea haurrek 14 hilabeterekin azpieskala mentalean puntuazio altuagoak izatearekin lotu zen (BSID) [27]. Gernuko iodo kontzentrazioei dagokienez, haurdunaldian zehar amak $<100 \mu \mathrm{g} / 1$ izatea 4 urtetan haurren garapen baxuago batekin asoziatu zen (MSCA) [28]. Emaitza hauek bat datoz egun dagoen ebidentziarekin [57].

\subsubsection{Jaio aurretik azido folikoaren aurrean izandako esposizioa eta garapen neuropsikologikoa haurtzaroan}

Azido folikoa oinarrizko beste elikagai bat da. 90eko hamarkadan azido folikoak garrantzia hartu zuen eta haurdunaldian zehar sustantzia hau hartzearen garrantzia azpimarratu zen hodi neuraleko arazoak saihesteko batik bat [58].

INMA proiektuan, ikusi zen haurdunaldian eguneko azido folikoa 400$1.000 \mu \mathrm{g}$ dositan hartzen zuten emakumeen haurrek hobekuntzak zituztela 14 hilabeterekin (BSID) eta 4 urterekin (MSCA) haien garapen neuropsikologikoa ebaluatzean. Hala ere, gehiegizko dosia hartzea, azido foliko gutxiegi hartzea bezala, kaltegarria zela ikusi zen [29-30]. Gure proiektuko ikerketen emaitzen ildo beretik doazen beste batzuk ere badaude [59].

\subsubsection{Edoskitze naturala eta haurraren garapen neuropsikologikoa}

Edoskitze naturala onuragarria da amaren osasunerako eta haurraren osasun eta garapenerako [60].

Edoskitze naturala eta haurtzaroan haurrak garatutako ADHN sintomatologiaren arteko asoziazioa aztertzen duten ikerketa gutxi dago, baina bada edoskitzearen iraupena autismoaren sintomatologiarekin lotura negatiboa duela dion ikerketa bat [61]. INMA proiektuan garatutako lan batean ikusi zen edoskitze naturalaren eta haurrek 4 urterekin zuten garapen kognitiboaren (MCSA) artean asoziazio positiboa zegoela; eta negatiboa, ordea, haurren ADHN eta autismoaren (CAST) sintomatologiarekin [31]. Emaitza 
Izaro Babarro et al.

hauek bat datoz beste ikerketa batzuetan aurkitutakoekin [62]; hala ere, Estatu Batuetan burututako ikerketa batek ez zuen asoziaziorik aurkitu [63].

\section{ONDORIOAK}

Emakumeen bizi-ohiturei lotutako bi eragilek (gainpisu/obesitateak eta erretze-ohiturak) asoziazio negatiboa erakutsi zuten haurraren garapen neuropsikologikoarekin. Elikadura-ohiturei dagokienez, ikusi da arraina osasunerako onuragarriak zein kaltegarriak diren substantzien garraio dela. Horregatik, komenigarria da haurdunek arrainen kontsumo egokia (astean 3 erraziotik gorakoa) izatea eta gantz-azido maila altuak/merkurio maila baxuak dituzten arrainak hautatzea, hala nola, izokina, amuarraina edo sardina.

Bestetik, osasun-sistemaren jarraibideei dagokienez, gure proiektuko emaitzek azido folikoak zein iodoak haurren garapenean eragina dutela ikusi zen. Edoskitze naturalak autismoa bezalako jokabide-arazoentzat paper babesgarria zuela erakutsi zuten gure ikerketek.

Ingurumeneko faktoreei dagokienez, haurraren garapenean eta osasunean eraginak dituztela ikusi da. Proiektua aitzindari izan da honako bi asoziazio hauek ezartzen: alde batetik, ura desinfektatzeko erabiltzen diren produktuen eta haurraren garapen neuropsikologikoaren arteko asoziazioa; eta bestetik, gune berdeen gertutasuna eta haurraren garapen neuropsikologikoaren arteko asoziazioa.

Honelako lan prospektiboek eragile desberdinek pertsonen garapenean duten garrantzia ikusarazten du eta, bide batez, pertsonek beren bizi-ohiturekiko eta ingurumenarekiko jarrera osasuntsu eta egokia izan dezaten sustatzea bilatzen du.

\section{ESKER ONAK}

INMA proiektua posible egin duten familia eta haurrei eta, azpikohorte desberdinetan, ospitale eta osasun-zentroetan lan asistentziala aurrera eramaten duten langileei gure esker onak adierazi nahi genizkieke.

Baita proiektu hau aurrera eramateko beren oniritzia eta finantziazioa eman duten erakundeei ere: Carlos III Osasun Institutua (Red INMA G03/176, FIS-PI041436, PI06/0867, PI081151, PI09/00090, PI09/02311, PI11/0610, PI13/02187, PI13/02406, PI13/02429, PI13/1944, PI13/2032, PI14/0891, PI14/1687, PI16/1288, CB06/02/0041), Miguel Servet Fundazioa-FEDER MS15/0025, MS16/00085, MS13/00054), Valentziako Generalitatea (FISABIO UGP 15-230), Kataluniako Generalitatea- 
Haurdunaldian amak izandako bizi-ohiturak, ingurumen-esposizioak, osasun-sistemaren ekimenak eta haurraren garapen neuropsikologikoa

CIRT 1999SGR 00241, Eusko Jaurlaritzako Osasun Saila (2005111093, 2009111069, 2013111089 eta 2015111065) eta Gipuzkoako Aldundia (DFG06/002, DFG08/001 eta DFG15/221).

\section{BIBLIOGRAFIA}

[1] VILLAR M. 2011. «Factores determinantes de la salud: Importancia de la prevención». Med. Per, 28, 237-41.

[2] GUXENS M., MENDEZ M.A., MOLTÓ-PUIGMARTÍ C., JULVEZ J., GARCÍA-ESTEBAN R., FORNS J. et al. 2011. «Breastfeeding, Long-Chain Polyunsaturated Fatty Acids in Colostrum, and Infant Mental Development». Pediatrics, 128, e880-9. doi:10.1542/peds.2010-1633.

[3] BAYLEY N. 1977. Escalas Bayley de Desarrollo Infantil. BSID. Madril: TEA.

[4] MCCARTHY D. 2009. Escalas McCarthy de Aptitudes y Psicomotricidad para Niños : manual MSCA. Madril: TEA.

[5] SCOTT FJ, BARON-COHEN S, BOLTON P, BRAYNE C. 2002. «CAST (Childhood Asperger Syndrome Test): Preliminary Development of a UK Screen for Mainstream PrimarySchool-Age Children». Autism, 6, 9.

[6] RUEDA MR, FAN J, MCCANDLISS BD, HALPARIN JD, GRUBER DB, LERCARI LP, POSNER MI. 2004. «Development of attentional networks in childhood». Neuropsychologia, 42, 1029-40.

[7] KIRCHNER W. 1958. «Age differences in short-term retention of rapidly changing information». Journal of Experimental Psychology, 55, 352.

[8] CONNERS CK. 1989. «Conners' Rating Scales». Ontario: MultiHealth Systems.

[9] JULVEZ J, MÉNDEZ M, FERNANDEZ-BARRES S, ROMAGUERA D, VIOQUE J, LLOP S. et al. 2016. «Maternal Consumption of Seafood in Pregnancy and Child Neuropsychological Development: A Longitudinal Study Based on a Population With High Consumption Levels». Am J Epidemiol, 183, 169-182. doi:10.1093/aje/kwv195

[10] LLOP S, BALLESTER F, MURCIA M, FORNS J, TARDON A, ANDIARENA A. et al. 2017. «Prenatal exposure to mercury and neuropsychological development in young children : the role of fish consumption». Int J Epidemiol, 46, 827-838. doi:10.1093/ije/dyw259

[11] CASAS, M., CHATZI, L., CARSIN, AE., AMIANO, P., GUXENS, M., KOGEVINAS, M. et al. 2013. «Maternal pre-pregnancy overweight and obesity, and child neuropsychological development : two Southern European birth cohort studies». Int J Epidemiol, 42, 506-17. doi:10.1093/ije/ dyt002

[12] CASAS M, FORNS J, MARTÍNEZ D, GUXENS M, FERNANDEZ-SOMOANO A, IBARLUZEA J, LERTXUNDI N. et al. 2017. «Maternal prepregnancy obesity and neuropsychological development in pre-school chil- 
Izaro Babarro et al.

dren: A prospective cohort study». Pediatr Res, 82, 596-606. doi:10.1038/ pr.2017.118

[13] EZQUIAGA, H. AURREKOETXEA, JJ. ESPADA M., IBARLUZEA J. 2017. «Arreta-defizitaren eta hiperaktibitatearen nahasmendua lau urteko umeengan eta haurdunaldiko tabako-kontsumoa». Osagaiz, 2, 33-42.

[14] AURREKOETXEA J, MURCIA M, LERTXUNDI N, GUXENS M, ESTARLICH M, JULVEZ J, FERNÁNDEZ-SOMOANO A, SANTA-MARINA L, DELCOS GL, TARDÓN A, ESPADA M, SUNYER J, IBARLUZEA J. Argitaratzeke. «Smoking during pregnancy and behavioural disorder symptoms including attention deficit hyperactivity disorder in preschool and school age children»

[15] ARANBARRI, A, FANO, E, LLOP, S, RAMÓN, R, MURCIA, M, GUXENS, M. et al. 2012. «Compuestos orgánicos persistentes y metales pesados en sangre y efectos en el desarrollo neuropsicológico de la primera infancia en las cohortes de madres-niños INMA (INfancia y Medio Ambiente)». Rev. salud ambient, 12, 3-13.

[16] FORNS J, LERTXUNDI N, ARANBARRI A, MURCIA M, GASCON M, MARTINEZ D. et al. 2012. «Prenatal exposure to organochlorine compounds and neuropsychological development up to two years of life». Environ Int, , 45, 72-7. doi:10.1016/j.envint.2012.04.009

[17] FREIRE C, AMAYA E, GIL F, FERNÁNDEZ MF, MURCIA M, LLOP S. et al. 2018. «Prenatal co-exposure to neurotoxic metals and neurodevelopment in preschool children : The Environment and Childhood (INMA) Project». Sci Total Environ, 621, 340-51. doi:10.1016/j. scitotenv.2017.11.273

[18] GUXENS M, AGUILERA I, BALLESTER F, ESTARLICH M, FERNÁNDEZ-SOMOANO A, LERTXUNDI A. et al. 2012. «Prenatal Exposure to Residential Air Pollution and Infant Mental Development : Modulation by Antioxidants and Detoxification Factors». Environ Health Perspect, 120, 144-9. doi: 10.1289/ehp.1103469

[19] LERTXUNDI A, BACCINI M, LERTXUNDI N, FANO E, ARANBARRI A, MARTÍNEZ MD. et al. 2015. «Exposure to fine particle matter, nitrogen dioxide and benzene during pregnancy and cognitive and psychomotor developments in children at 15 months of age». Environ Int, 80, 33-40. doi:10.1016/j.envint.2015.03.007

[20] LLOP S, GUXENS M, MURCIA M, LERTXUNDI A, RAMON R, RIAÑO I. et al. 2012. «Prenatal Exposure to Mercury and Infant Neurodevelopment in a multicenter cohort in Spain : Study of Potential Modifiers». Am J Epidemiol, 175,:451-65. doi:10.1093/aje/kwr328

[21] DADVAND P, TISCHER C, ESTARLICH M, LLOP S, DALMAUBUENO A, LÓPEZ-VICENTE M. et al. 2017. «Lifelong Residential Exposure to Green Space and Attention : A Population-based Prospective Study». Environ Health Perspect, 125, e097016. 
Haurdunaldian amak izandako bizi-ohiturak, ingurumen-esposizioak, osasun-sistemaren ekimenak eta haurraren garapen neuropsikologikoa

[22] SENTÍS A, SUNYER J, DALMAU-BUENO A, ANDIARENA A. 2017. «Prenatal and postnatal exposure to NO 2 and child attentional function at 4-5 years of age». Environ Int, 106, 170-7. doi:10.1016/j.envint.2017.05.021

[23] VILAHUR N, FERNÁNDEZ MF, BUSTAMANTE M, RAMOS R, FORNS J, BALLESTER F. et al. 2014. «In utero exposure to mixtures of xenoestrogens and child neuropsychological development». Environ Res, 134, 98-104. doi:10.1016/j.envres.2014.07.002

[24] VILLANUEVA CM, GRACIA-LAVEDAN E, JULVEZ J, SANTA-MARINA L, LERTXUNDI N, IBARLUZEA J. et al. 2017. «Drinking water disinfection by-products during pregnancy and child neuropsychological development in the INMA Spanish cohort study». Environ Int, 110, 113-22. doi:10.1016/j.envint.2017.10.017

[25] CASAS M, FORNS J, MARTÍNEZ D, AVELLÁ-GARCIA C, VALVI D, BALLESTEROS-GOMEZ A, LUQUE N, RUBIO S, JULVEZ J, SUNYER J, VRIJHEID M. 2015. «Exposure to bisphenol A during pregnancy and child neuropsychological development in the INMA-Sabadell cohort». Environmental Research. 142, 671-679.

[26] MURCIA M, REBAGLIATO N, IÑIGUEZ C, LOPEZ-ESPINOSA M, ESTARLICH M, PLAZA B. et al. 2011. «Effect of Iodine Supplementation During Pregnancy on Infant Neurodevelopment at 1 Year of Age». Am J Epidemiol, 173, 804-12 doi:10.1093/aje/kwq424

[27] REBAGLIATO M, MURCIA M, ALVAREZ-PEDREROL M, ESPADA M, FERNÁNDEZ-SOMOANO A, LERTXUNDI N. et al. 2013. «Iodine Supplementation During Pregnancy and Infant Neuropsychological Development. INMA Mother and Child Cohort Study». Am J Epidemiol, 177, 944-53. doi:10.1093/aje/kws333

[28] MURCIA M, ESPADA M, JULVEZ J, LLOP S, LOPEZ-ESPINOSA MJ, VIOQUE J. et al. 2018. «Iodine intake from supplements and diet during pregnancy and child cognitive and motor development : the INMA Mother and Child Cohort Study». J Epideimiol Community Health, 72, 216-222. doi:10.1136/jech-2017-209830

[29] VALERA-GRAN D, GARCÍA DE LA HERA M, NAVARRETE-MUÑOZ EM, FERNANDEZ-SOMOANO A, TARDÓN A, JULVEZ J. et al. 2014. «Folic Acid Supplements During Pregnancy and Child Psychomotor Development After the First Year of Life». JAMA Pediatr, 168, e142611. doi:10.1001/jamapediatrics.2014.2611

[30] VALERA-GRAN D, NAVARRETE-MUÑOZ E, GARCIA DE LA HERA M, FERNANDEZ-SOMOANO A, TARDÓN A, IBARLUZEA J. et al. 2017. «Effect of maternal high dosages of folic acid supplements on neurocognitive development in children at 4-5 years of age : the prospective birth cohort Infancia y Medio Ambiente (INMA) study». Am J Nutr, 106, 878887. doi:10.3945/ajen.117.152769

[31] BOUCHER O, JULVEZ J, GUXENS M, ARRANZ E, IBARLUZEA J, SÁNCHEZ DE MIGUEL M. et al. 2017. «Association between breastfeed- 
Izaro Babarro et al.

ing duration and cognitive development, autistic traits and ADHD symptoms: a multicenter study in Spain». Pediatr Res, 81, 434-442. doi:10.1038/ pr.2016.238

[32] JULVEZ J, GUXENS M, CARSIN AE, FORNS J, MENDEZ M, TURNER MC, SUNYER J. 2014. «A cohort study on full breastfeeding and child neuropsychological development: the role of maternal social, psychological and nutritional factors». Developmental Medicine \& Child neurolovy. 56, 148156.

[33] GUXENS M, MENDEZ MA, MOLTÓ-PUIGMARTÍ C, JULVEZ J, GARCÍA-ESTEBAN J, FORNS J, FERRER M, VRIJHEID M, LOPEZSABATER MC, SUNYER J. 2011. «Breastfeeding, Long-Chain Polyunsaturated Fatty Acids in Colostrum, and Infant Mental Development». Pediatrics. 128, e880.

[34] AVELLA-GARCIA CB, JULVEZ J. 2014. «Seafood Intake and Neurodevelopment: A Systematic Review». Current Environmental Health Reports, 1, 46-77. doi:10.1007/s40572-013-0006-4

[35] LEDERMAN SA, JONES RL, CALDWELL KL, RAUH V, SHEETS SE, TANG D. et al. 2008. «Relation between Cord Blood Mercury Levels and Early Child Development in a World Trade Center Cohort». Environ Health Perspect, 116, 1085-91. doi:10.1289/ehp.10831

[36] OKEN E, RADESKY JS, WRIGHT RO, BELLINGER DC, AMARASIRIWARDENA CJ, KLEINMAN KP. et al. 2009. «Maternal fish intake during pregnancy, blood mercury levels, and child cognition at age 3 years in US cohort». Am J Epidemiol, 167, 1171-81. doi:10.1093/aje/kwn034

[37] BERGHÖFER A, PISCHON T, REINHOLD T, APOVIAN CM, SHARMA AM, WILLICH SN. 2008. «Obesity prevalence from a European perspective: asystematic review». BMC Public Health, 8:200. doi:10.1186/14712458-8-200.

[38] HINKLE SN, SHARMA AJ, SWAN DW, SCHIEVE LA, RAMAKRISHNAN U, STEIN AD. 2012. «Excess Gestational Weight Gain Is Associated with Child Adiposity among Mothers with Normal and Overweight Prepregnancy Weight Status». J Nutr, 142,:1851-8. doi:10.3945/ jn.112.161158

[39] KAAR JL, CRUME T, BRINTON JT, BISCHOFF KJ, MCDUFFIE R, DABELEA D. 2014. «Maternal obesity, gestational weight gain, and offspring adiposity: The exploring perinatal outcomes among children study». J Pediatr, 165, 509-15. doi:10.1016/j.jpeds.2014.05.050

[40] BRION M, ZEEGERS M, JADDOE V, VERHULST F, LAWLOR DA, SMITH GD. 2011. «Maternal Pre-pregnancy Overweight and Child Cognition and Behavior: Exploring Intrauterine Effects in Two Pregnancy Cohorts». Pediatrics, 127, e202-e211. doi:10.1542/peds.2010-0651

[41] ORTEGA J., FERRIS J, BERBEL O, ROMERO KJ, RUBALCAVA L, MARTÍNEZ E. et al. 2006. «Neurotóxicos medioambientales (IV)*. Tabaco, alcohol, solventes , flúor y aditivos alimentarios: efectos adversos en el sis- 
Haurdunaldian amak izandako bizi-ohiturak, ingurumen-esposizioak, osasun-sistemaren ekimenak eta haurraren garapen neuropsikologikoa

tema nervioso fetal y posnatal y medidas preventivas». Acta Pediatr Esp, 64, 493-502.

[42] KEYES K., DAVEY SMITH G, SUSSER E. 2014. «Associations of prenatal maternal smoking with offspring hyperactivity: causal or confounded?». Psychol Med, 44, 857-67. doi: 10.1017/S0033291713000986

[43] TIESLER CM, HEINRICH J. 2014. «Prenatal nicotine exposure and child behavioural problems». Eur Child Adolesc Psychiatry, 23, 913-29. doi:10.1007/s00787-014-0615-y

[44] BERGONZI R, DE PALMA G, SPECCHIA C, DINOLFO M, TOMASI C, FRUSCA T. et al. 2011. «Persistent organochlorine compounds in fetal and maternal tissues: Evaluation of their potential influence on several indicators of fetal growth and health». Sci Total Environ, , 409, 2888-93. doi:10.1016/j. scitotenv.2011.04.031

[45] GASCON M, VERNER MA, GUXENS M, GRIMALT JO, FORNS J, IBARLUZEA J. et al. 2013. «Evaluating the neurotoxic effects of lactational exposure to persistent organic pollutants (POPs) in Spanish children». Neurotoxicology, 34, 9-15. doi:10.1016/j.neuro.2012.10.006

[46] PARK HY, HERTZ-PICCIOTTO I, SOVCIKOVA E, KOCAN A, DROBNA B, TRNOVEC T. 2010. «Neurodevelopmental toxicity of prenatal polychlorinated biphenyls (PCBs) by chemical structure and activity: a birth cohort study». Environ Health, 23, 51. doi:10.1186/1476-069X-9-51.

[47] ZHANG H, YOLTON K, WEBSTER GM, SJÖDIN A, CALAFAT AM, DIETRICH KN. 2017. «Prenatal PBDE and PCB Exposures and Reading, Cognition, and Externalizing Behavior in Children» Environ Health Perspect, 125, 746-52.

[48] EDWARDS SC, JEDRYCHOWSKI W, BUTSCHER M, CAMANN D, KIELTYKA A, MROZ E. et al. 2010. «Prenatal exposure to airborne polycyclic aromatic hydrocarbons and children's intelligence at 5 years of age in a prospective cohort study in Poland». Environ Health Perspect, 118, 1326-31. doi:10.1289/ehp.0901070

[40] KIM E, PARK H, HONG YC, HA M, KIM Y, KIM BN. et al. 2014. «Prenatal exposure to $\mathrm{PM}_{10}$ and $\mathrm{NO}_{2}$ and children's neurodevelopment from birth to 24 months of age: Mothers and Children's Environmental Health (MOCEH) study». Sci Total Environ, 481, 439-45. doi:10.1016/j.scitotenv.2014.01.107

[50] DADVAND P, RIVAS I, BASAGAÑA X, ALVAREZ-PEDREROL M, SU J, DE CASTRO PASCUAL M. et al. 2015. «The association between greenness and traffic-related air pollution at schools». Sci Total Environ, 523, 59-63. doi:10.1016/j.scitotenv.2015.03.103

[51] DADVAND P, SUNYER J, BASAGAÑA X, BALLESTER F, LERTXUNDI A, FERNÁNDEZ-SOMOANO A. et al. 2012. «Surrounding greenness and pregnancy outcomes in four Spanish birth cohorts». Environ Health Perspect, 120, 1481-7. doi:10.1289/ehp.1205244

[52] JAMES AC, JAMES G, COWDREY FA, SOLER A, CHOKE A. 2015. «Cognitive behavioural therapy for anxiety disorders in chil- 
Izaro Babarro et al.

dren and adolescents (eview)». Cochrane Database Syst Rev, 2, 1-108. doi:10.1002/14651858.CD004690.pub4

[53] MAAS J, VERHEIJ RA, DE VRIES S, SPREEUWENBERG P, SCHELLEVIS FG, GROENEWEGEN PP. 2009. «Morbidity is related to a green living environment». J Epidemiology Community Heal. 63, 967-73. doi:10.1136/ jech.2008.079038

[54] WU CD, MCNEELY E, CEDEÑO-LAURENT JG, PAN WC, ADAMKIEWICZ G, DOMINICI F. et al. 2014. «Linking student performance in Massachusetts elementary schools with the "greenness» of school surroundings using remote sensing». PLoS One, 9, e108548. doi:10.1371/journal. pone. 0108548

[55] VILLANUEVA CM, CORDIER S, FONT-RIBERA L, SALAS LA, LEVALLOIS P. 2015 «Overview of Disinfection By-products and Associated Health Effects». Curr Environ Heal Rep, 2, 107-15. doi:10.1007/s40572014-0032-x

[56] LEVIE D, KOREVAAR TIM, BATH SC, DALMAU-BUENO A, MURCIA M, ESPADA M. et al. 2018. «Thyroid Function in Early Pregnancy, Child IQ, and Autistic Traits: a Meta-analysis of Individual-participant Data». J Clin Endocrinol Metab, 103, 2967-79. doi:10.1210/jc.2018-00224

[57] ZHANG L, TENG W, LIU Y, LI J, MAO J, FAN C. et al. 2012. «Effect of maternal excessive iodine intake on neurodevelopment and cognitive function in rat offspring». BMC Neurosci, 13, 121. doi:10.1186/1471-2202-13121

[58] REYNOLDS E. 2006. «Vitamin B12, folic acid, and the nervous system». Lancet Neurol, 5, 949-60. doi:10.1016/S1474-4422(06)70598-1

[59] VILLAMOR E, RIFAS-SHIMAN SL, GILLMAN MW, OKEN E. 2012 «Maternal intake of methyl-donor nutrients and child cognition at 3 years of age». Paediatr Perinat Epidemiol, 26, 32835. doi:10.1111/j.1743-6109.2008.01122.x

[60] STUEBE AM, SCHWARZ EB. 2010. «The risks and benefits of infant feeding practices for women and their children». J Perinatol, 30, 155-62. doi:10.1038/jp.2009.107

[61] STEINMAN G, MANKUTA D. 2013. «Breastfeeding as a possible deterrent to autism - A clinical perspective». Med Hypotheses, 81, 999-1001. doi:10.1016/j.mehy.2013.09.013

[62] KADZIELA-OLECH H, PIOTROWSKA-JASTRZEBSKA J. 2005 «The duration of breastfeeding and attention deficit hyperactivity disorder». Rocz Akad Med Białymst, 50, 302-6.

[63] HUSK JS, KEIM SA. 2015. «Breastfeeding and Autism Spectrum Disorder in the National Survey of Children's Health». Epidemiology, 26, 451-7. doi:10.1097/EDE.0000000000000290 